\title{
Activation and enzymatic characterization of recombinant human kallikrein 8
}

\author{
Tadaaki Kishi ${ }^{1,2,3}$, Sylvain M. Cloutier ${ }^{3,4}$, \\ Christoph Kündigg,4, David Deperthes ${ }^{3,4}$ and \\ Eleftherios P. Diamandis ${ }^{1,2, *}$,
}

\author{
${ }^{1}$ Department of Pathology and Laboratory Medicine, \\ Mount Sinai Hospital, Toronto M5G 1X5, ON, Canada \\ ${ }^{2}$ Department of Laboratory Medicine and Pathobiology, \\ University of Toronto, Toronto M5G 1L5, ON, Canada \\ ${ }^{3}$ Urology Research Unit, Department of Urology, CHUV, \\ $\mathrm{CH}-1011$ Lausanne, Switzerland \\ ${ }^{4}$ Med Discovery S.A., Biopôle, Chemin des Croisettes \\ 22, $\mathrm{CH}-1066$ Epalinges, Switzerland \\ *Corresponding author \\ e-mail: ediamandis@mtsinai.on.ca
}

\begin{abstract}
Human kallikrein 8 (hK8), whose gene was originally cloned as the human ortholog of a mouse brain protease, is known to be associated with diseases such as ovarian cancer and Alzheimer's disease. Recombinant human pro-kallikrein 8 was activated with lysyl endopeptidaseconjugated beads. Amino-terminal sequencing of the activated enzyme demonstrated the cleavage of a 9-aa propeptide from the pro-enzyme. The substrate specificity of activated hK8 was characterized using synthetic fluorescent substrates. hK8 showed trypsin-like specificity, as predicted from sequence analysis and enzymatic characterization of the mouse ortholog. All synthetic substrates tested containing either arginine or lysine at P1 position were cleaved by hK8. The highest $k_{\text {cat }} / K_{\mathrm{m}}$ value of $20 \times 10^{3} \mathrm{M}^{-1} \mathrm{~s}^{-1}$ was observed with Boc-Val-Pro-Arg-7amido-4-methylcoumarin. The activity of hK8 was inhibited by antipain, chymostatin, and leupeptin. The concentration for $50 \%$ inhibition by the best inhibitor, antipain, was $0.46 \mu \mathrm{M}$. The effect of different metal ions on the enzyme activity was analyzed. Whereas $\mathrm{Na}^{+}$had no effect on hK8 activity, $\mathrm{Ni}^{2+}$ and $\mathrm{Zn}^{2+}$ decreased the activity and $\mathrm{Ca}^{2+}, \mathrm{Mg}^{2+}$, and $\mathrm{K}^{+}$had a stimulatory effect. $\mathrm{Ca}^{2+}$ was the best activator, with an optimal concentration of approximately $10 \mu \mathrm{M}$.
\end{abstract}

Keywords: cancer biomarkers; human kallikrein 8; human kallikreins; $k_{\text {cat }} / K_{\mathrm{m}}$; lysyl endopeptidase; serine protease.

\section{Introduction}

In 1995 a protease was cloned from mouse hippocampus cDNA and named neuropsin owing to its expression

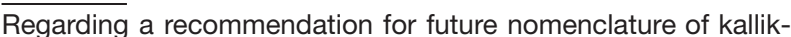
rein gene-derived proteases, see the article 'A comprehensive nomenclature for serine proteases with homology to tissue kallikreins' by Lundwall et al., this issue pp. 637-641.
}

in neurons and its predicted trypsin-like specificity (Chen et al., 1995). The expression level of this enzyme depends on electrical stimulation and oxidative stress within the limbic system (Chen et al., 1995; Akita et al., 1997). In kindling mice, a model for plasticity and epilepsy, the expression was found to be induced in several areas of the brain (Okabe et al., 1996) and the progression of the kindling stage was inhibited by intraventricular injection of monoclonal antibodies specific to neuropsin (Momota et al., 1998). Therefore, the enzyme is believed to be associated with brain function, such as memory formation. Recombinant neuropsin was previously expressed in a baculovirus expression system and characterized as a trypsin-like protease, both enzymatically and structurally (Shimizu et al., 1998; Kishi et al., 1999). The human and rat orthologs were also cloned (Davies et al., 1998; Yoshida et al., 1998).

Recently, the human ortholog was identified as a new member of the human kallikrein gene family and was named human kallikrein 8 (symbols $K L K 8$ for the gene and hK8 for the protein) (Diamandis et al., 2000a). hK8 is predicted to be translated into a 250 -aa pre-proenzyme, which is activated by the removal of an $\mathrm{N}$-terminal prepropeptide. The predicted active hK8 is 228 aa long and contains a putative catalytic triad (His, Asp and Ser) typical for trypsin-like serine proteases. Trypsin-like activity was also demonstrated for the mouse ortholog mK8. Recombinant pro-hK8 was expressed using a baculovirus expression system, and then purified and used to develop specific antibodies (Kishi et al., 2003b). By applying an enzyme-linked immunosorbent assay (ELI$\mathrm{SA}$ ) using these antibodies, hK8 was found to be expressed in several tissues and biological fluids, indicating that this protease is expressed physiologically and might be associated with different biological functions or diseases.

Most human kallikrein members are suggested to be linked to various cancers, such as testicular, lung, colon, cervix, breast, ovarian, and/or prostate cancer, and might prove useful as biomarkers for diagnosis and prognosis (Borgono and Diamandis, 2004). In particular, prostate specific antigen (PSA)/human kallikrein 3 (hK3) is an established biomarker for prostate cancer diagnosis and prognosis. hK8 was reported to be a candidate biomarker for breast (Yousef et al., 2004b), cervix (Cane et al., 2004), colon (Yousef et al., 2004a) and ovarian cancers (Underwood et al., 1999) at the mRNA level, and ovarian cancer (Kishi et al., 2003a) at the protein level. Furthermore, it has also been suggested that this enzyme is also associated with Alzheimer's disease (Shimizu-Okabe et al., 2001).

In this study, conditions for the activation of recombinant pro-hK8 are reported and the substrate specificity of activated hK8 was investigated in detail with synthetic substrates and inhibitors. This report, along with a recent 
publication (Rajapakse et al., 2005), describes the detailed enzymatic characterization of hK8, confirming its trypsin-like specificity. This work will facilitate identification of potential natural substrates and physiological functions of hK8.

\section{Results}

\section{Inhibition of lysyl endopeptidase (Lys-C) activity in supernatant by TLCK}

To inactivate any leakage of Lys-C activity from hK8 activation beads into the supernatant, we determined the minimal concentration of TLCK (1-chloro-3-tosylamido7-amino-2-heptanone $\mathrm{HCl}$ ) necessary to inhibit active Lys-C. At concentrations up to $1 \mathrm{~nm}$ there was no detectable effect of TLCK on Lys-C activity in the supernatant. An inhibitor concentration of $1 \mu \mathrm{M}$ was sufficient to completely inhibit all residual Lys-C activity (data not shown).

\section{Optimization of hK8 activation with Lys-C- conjugated beads}

To determine optimal activating conditions for hK8, prohK8 was incubated with Lys-C conjugated beads for varying periods of time. The highest enzyme activity of activated hK8, measured with Boc-Val-Pro-Arg-AMC, was observed after 30 min of incubation, with a slight decrease after 60 min of incubation (Figure 1A). The hK8 activity at each time point was confirmed by analysis of the complex formation between hK8 and a serpin-type inhibitor that binds covalently to active hK8. The formation of complexes between hK8 and the $\alpha 1$-antichymotrypsin variant containing a protein $\mathrm{C}$ inhibitor-derived modification of the reactive site loop sequence P3-P2' $[\mathrm{ACT}(\mathrm{PCl})]$ was observed after 15-min incubation with Lys-C (Figure 1B). After 60 min of incubation, an additional protein band at approximately $24 \mathrm{kDa}$ appeared, which likely represents a degradation product of hK8.

\section{Activation of recombinant hK8}

To determine the fraction of active hK8 within the enzyme preparation, complex formation experiments with the hK8 inhibitor $\mathrm{ACT}(\mathrm{PCl})$ were performed. Recombinant $\mathrm{ACT}(\mathrm{PCl})$, an $\alpha 1$-antichymotrypsin variant containing a reactive site loop modification derived from protein $\mathrm{C}$ inhibitor, has been described as an inhibitor of hK2 (Cloutier et al., 2004). Besides its inhibitory activity on hK2, $\mathrm{ACT}(\mathrm{PCl})$ also inhibits other human tissue kallikreins, including $\mathrm{hK} 8$, by forming stable complexes (unpublished data). ACT(PCl) was used to quantify active hK8. The fraction of active hK8 complexed with $\mathrm{ACT}(\mathrm{PCl})$ was estimated to be approximately $95 \%$ (Figure 2). A very faint protein band at approximately $24 \mathrm{kDa}$ most likely represents degraded hK8.

\section{$\mathrm{N}$-Terminal sequencing of the pro-form and active hK8}

Activation of hK8 was assessed by determination of its $\mathrm{N}$-terminal sequences. The $\mathrm{N}$-terminus of pro-hK8 was
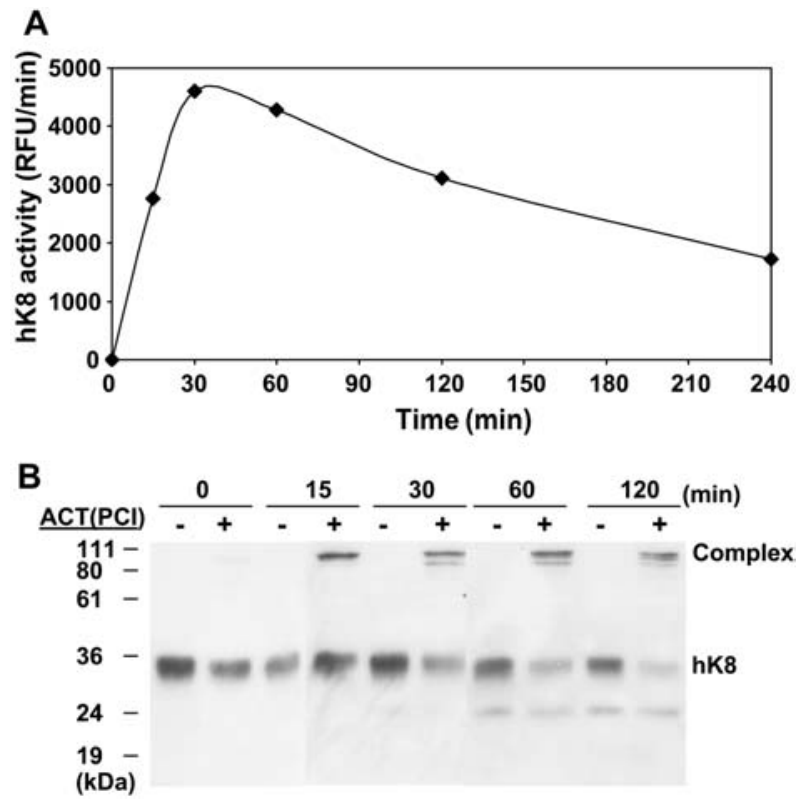

Figure 1 Activation conditions for human kallikrein 8. Influence of incubation time with Lys-C beads on hK8 activity. (A) hK8 activity evaluated by cleavage of the synthetic substrate Boc-Val-Pro-Arg-AMC. RFU, relative fluorescence units. (B) hK8 activity evaluated by covalent complex formation with an $\alpha 1$ antichymotrypsin variant, $\mathrm{ACT}(\mathrm{PCl})$. The bands were detected with a rabbit polyclonal antibody specific for hK8.

identified as Gly-His-Ser-Arg-Ala-Gln-Glu-Asp-Lys-ValLeu, while that of activated hK8 was Val-Leu-Gly-GlyHis-Glu. These amino acid sequences correspond to those predicted for hK8 (aa 24-38, SwissProt accession no. O60259) (Figure 3). The Lys-C cleavage site was

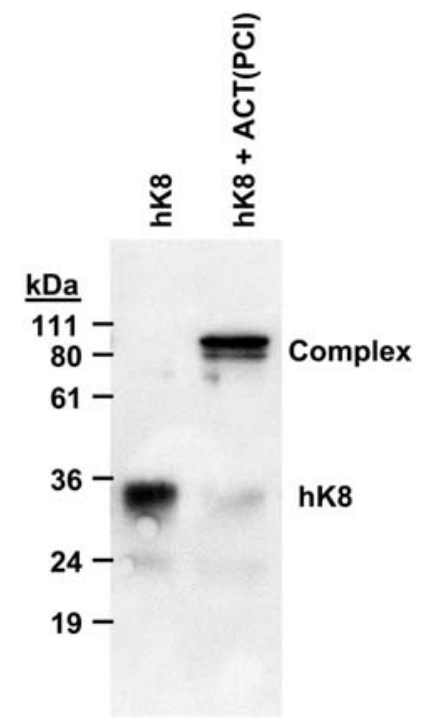

Figure 2 Determination of the fraction of active hK8 after activation.

Lane 1, free hK8 preparation; lane 2, hK8 complexed with an $\alpha 1$-antichymotrypsin variant, $\mathrm{ACT}(\mathrm{PCl})$. The samples were blotted onto nitrocellulose membranes after SDS-PAGE separation and detected using rabbit anti-hK8 antibody. For details, see the text. The ratio of inactive hK8 that did not complex with $\mathrm{ACT}(\mathrm{PCl})$ was evaluated to be less than $5 \%$ of total hK8. 
found to be identical to the activation site predicted by gene analysis (Yoshida et al., 1998).

\section{Determination of pH optimum for activated hK8}

The influence of $\mathrm{pH}$ on hK8 activity was examined within the range $\mathrm{pH} 5-10$ (Figure 4). There was no detectable activity below $\mathrm{pH}$ 5.5. The $\mathrm{pH}$ optimum was approximately 8.5. The activity dropped to approximately $50 \%$ of that at the $\mathrm{pH}$ optimum at $\mathrm{pH} 7.4$ and 10.0.

\section{Enzyme analysis and substrate specificity}

The substrate specificity of hK8 was studied using six synthetic substrates. The catalytic activity values for hK8 using the substrates analyzed are summarized in Table 1. The highest $k_{\text {cat }} / K_{\mathrm{m}}$ value of $2.1 \pm 0.3 \times 10^{4} \mathrm{M}^{-1} \mathrm{~s}^{-1}$ was found for the substrate Boc-Val-Pro-Arg-AMC (residue numbers of the substrates are defined as follows: Pn ... P3-P2-P1-P1'-P2'-P3' ... Pn', with cleavage occurring at the $\mathrm{P} 1-\mathrm{P} 1^{\prime}$ bond). Lower activity was found with Z-Phe-

Prepro- $h K 8$

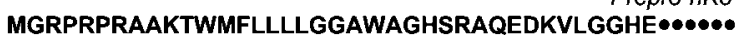

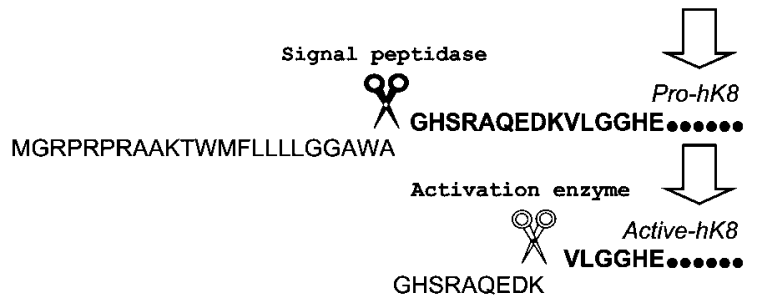

Figure 3 Activation model for human kallikrein 8.

The sequences are derived from the SwissProt protein database (accession no. 060259).

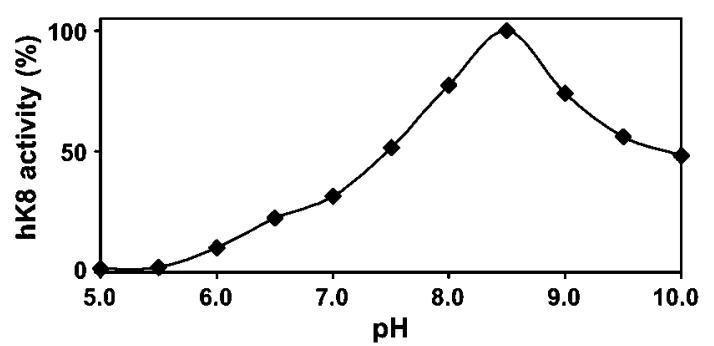

Figure $4 \mathrm{pH}$ dependence of human kallikrein 8 activity. hK8 activity was evaluated by cleavage of the synthetic substrate Boc-Val-Pro-Arg-AMC. At the $\mathrm{pH}$ optimum of 8.5 , the activity was defined as $100 \%$. A series of buffers was prepared to contain $25 \mathrm{~mm} \mathrm{CH}_{3} \mathrm{COOH}, 25 \mathrm{~mm}$ MES, $75 \mathrm{~mm}$ Tris, $25 \mathrm{~mm}$ glycine, $150 \mathrm{~mm} \mathrm{NaCl}$ and $0.05 \%$ Triton X-100.

Table 1 Substrate specificity of hK8.

\begin{tabular}{ll}
\hline Substrate & $k_{\text {cat }} / K_{\mathrm{m}}\left(\mathrm{M}^{-1} \mathrm{~s}^{-1}\right)^{\mathrm{a}}$ \\
\hline Z-Phe-Arg-AMC & $1.0 \times 10^{3}$ \\
Z-Gly-Gly-Arg-AMC & $1.0 \times 10^{3}$ \\
Suc-Ala-Ala-Pro-Phe-AMC & 0 \\
Boc-Val-Pro-Arg-AMC & $2.1 \times 10^{4}$ \\
MeSuc-Ala-Ala-Pro-Val-AMC & 0 \\
Tos-Gly-Pro-Lys-AMC & $6.7 \times 10^{2}$ \\
\hline
\end{tabular}

${ }^{\mathrm{a}} k_{\mathrm{cat}} / K_{\mathrm{m}}$ ratios were analyzed with $t_{3-1}(0.1)$.
Arg-AMC, Z-Gly-Gly-Arg-AMC and Tos-Gly-Pro-LysAMC. Substrates lacking basic amino acids in the P1 position, such as Suc-Ala-Ala-Pro-Phe-AMC and MeSuc-Ala-Ala-Pro-Val-AMC, were not cleaved by hK8.

\section{Effects of metal ions}

To evaluate the potential effect of metal ions on hK8 activity, Boc-Val-Pro-Arg-AMC cleavage was measured in the presence of varying concentrations of $\mathrm{CaCl}_{2}, \mathrm{KCl}$, $\mathrm{MgCl}_{2}, \mathrm{MgSO}_{4}, \mathrm{NaCl}, \mathrm{NiSO}_{4}$ and $\mathrm{ZnSO}_{4}$. The effects of metal ions on hK8 activity are summarized in Figure 5. $\mathrm{CaCl}_{2}, \mathrm{KCl}$ and $\mathrm{MgCl}_{2}$ had a positive effect on hK8 activity, with substrate cleavage efficiency increased by four-, three- and 1.7-fold, respectively. $\mathrm{NaCl}$ had no detectable effect up to a concentration of $1 \mathrm{M}$. $\mathrm{NiSO}_{4}$ and $\mathrm{ZnSO}_{4}$ caused a decrease in activity, with concentrations causing $50 \%$ inhibition $\left(\mathrm{IC}_{50}\right)$ of 11 and $3.3 \mu \mathrm{M}$, respectively (Figure 5B).

\section{Effect of protease inhibitors}

The effect of several commercial protease inhibitors on hK8 activity was tested (Figure 6). Whereas the two inhibitors against trypsin-like proteases, antipain and leupeptin, decreased hK8 activity in a dose-dependent manner, TLCK, another inhibitor of the same type, did not show any effect. Inhibition was also observed with chymostatin, a chymotrypsin-like protease inhibitor. Other inhibitors against metalloproteases (EDTA and phosphoramidon) and cysteine proteases (E-64) did not affect

\section{A}

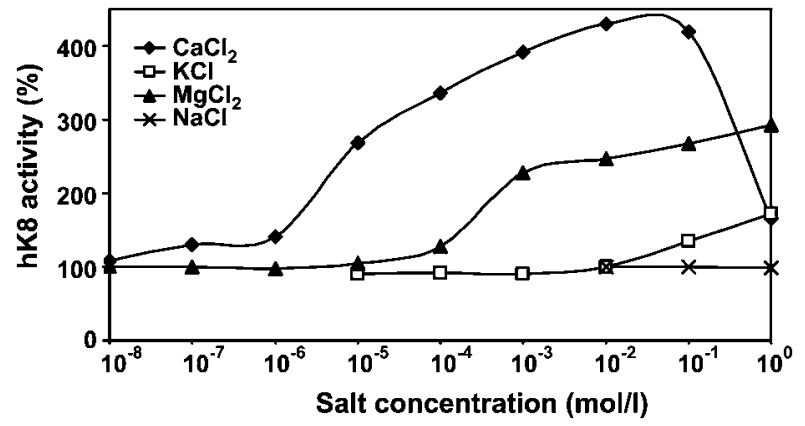

B

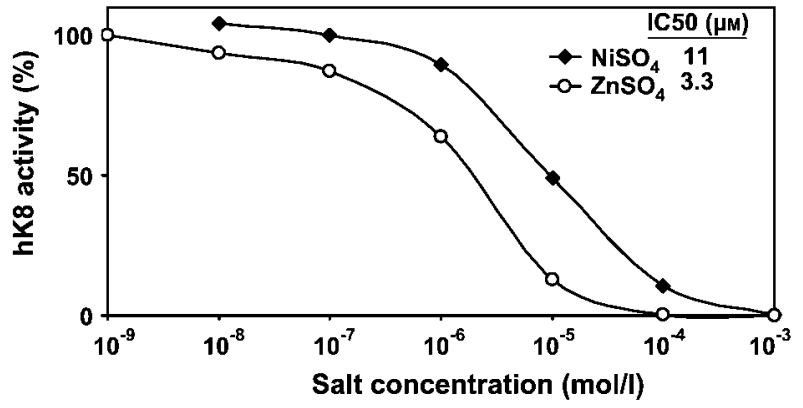

Figure 5 Effect of metal ions.

Relative activity was compared by $k_{\text {cat }} / K_{\mathrm{m}}$ measurements. The hK8 activity detected for $10 \mu \mathrm{M}$ Boc-Val-Pro-Arg-AMC substrate solution in $50 \mathrm{~mm}$ Tris- $\mathrm{HCl}$ buffer, $\mathrm{pH} 8.5$ at $37^{\circ} \mathrm{C}$ containing $0.05 \%$ Triton X-100 was defined as $100 \%$ activity. (A) Activation of hK8 by metal ions. $\mathrm{Na}^{+}$showed no detectable effect. (B) Inhibition of hK8 by metal ions. 


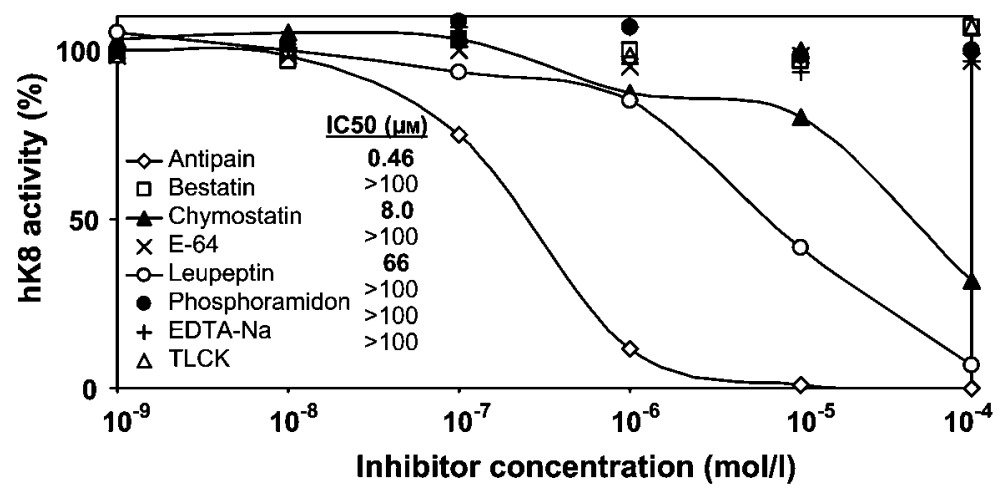

Figure 6 Inhibitor profiling of human kallikrein 8.

Relative activities were compared by $k_{\mathrm{cat}} / K_{\mathrm{m}}$ measurements. The hK8 activity detected for $10 \mu \mathrm{M}$ Boc-Val-Pro-Arg-AMC substrate solution in $50 \mathrm{~mm}$ Tris- $\mathrm{HCl}$ buffer, $\mathrm{pH} 8.5$ at $37^{\circ} \mathrm{C}$ containing $0.05 \%$ Triton X-100 without any inhibitor was defined as $100 \%$ activity.

hK8 activity. The $\mathrm{IC}_{50}$ values for antipain, chymostatin and leupeptin were $0.46,8.0$, and $66 \mu \mathrm{M}$, respectively.

\section{Discussion}

All human kallikreins have predicted pre-pro-peptides and are believed to be extracellular proteases. Most kallikreins, including hK8, have been detected in biological fluids as active enzymes or pro-enzymes (Stamey et al., 1987; Deperthes et al., 1995; Diamandis et al., 2000b, 2002; Luo et al., 2001; Borgono et al., 2003; Kapadia et al., 2003; Kishi et al., 2003b, 2004; Yousef et al., 2003; Obiezu et al., 2005). Recombinant hK8 was produced using a baculovirus expression system and was secreted into the culture medium as a pro-protein (Kishi et al., 2003b). One advantage of the baculovirus expression system is that, generally, post-translational modifications (removal of signal peptide, glycosylation, etc.) are carried out as for native proteins when a mammalian gene is expressed (Maeda, 1989). Sequence analysis predicted that hK8 has a pro-peptide of four amino acids (Glu29-Lys32; Yousef and Diamandis, 2001), but N-terminal sequencing of the recombinant hK8 expressed by the baculovirus system revealed the presence of an additional five amino acid residues. This 9-aa sequence may therefore constitute the native pro-peptide for hK8.

Optimal conditions for pro-hK8 activation with Lys-C beads were observed with a $45-\mathrm{min}$ incubation at $37^{\circ} \mathrm{C}$. Further increase in the incubation time led to a decrease in activity (Figure $1 \mathrm{~A})$. This decrease may be due to inactivating cleavage of active hK8 by Lys-C. Active hK8 contains a total of 15 Lys residues, three of which are positioned close to the active site of the enzyme (Yoshida et al., 1998). In the mouse ortholog, these Lys residues are predicted to be on a loop region (Kishi et al., 1999). Cleavage within this region would give rise to a C-terminal fragment of approximately $25 \mathrm{kDa}$, corresponding in size to the band detected by anti-hK8 antibody after prolonged incubation of hK8 with Lys-C (Figure 1B).

The amount of active hK8 was evaluated in band shift experiments evaluating complex formation of the protease with $\mathrm{ACT}(\mathrm{PCl})$ (Figures $1 \mathrm{~B}$ and 2). Shifted bands corresponding in size to $\mathrm{hK} 8-\mathrm{ACT}(\mathrm{PCl})$ complexes were detected. Additional shifted bands, likely to be degra- dation products of the hK8-ACT(PCl) complex, were detected after prolonged incubation of hK8 with Lys-C. It has been shown that the formation of serpin-protease complexes induces dramatic structural changes (Huntington et al., 2000), which may facilitate complex degradation by free proteases.

Like pro-hK8, the proenzymes of hK6, 7, 12, 13, 14 and 15 all have a Lys residue in their respective predicted activation-site P1 position (Yousef and Diamandis, 2001), suggesting the potential use of Lys-C in the activation of these zymogens. Indeed, recombinant hK7 and the mouse ortholog of hK8 (mK8) were previously shown to be activated by Lys-C (Hansson et al., 1994; Shimizu et al., 1998). Furthermore, crystallographic studies of the kallikreins hK1, hK6 and mK8 revealed very similar structures (Kishi et al., 1999; Bernett et al., 2002; Gomis-Ruth et al., 2002; Laxmikanthan et al., 2005). From sequence analysis of other kallikreins, it is believed that all of them share a very close ternary structure. This indicates that Lys-C might be able to access their activation sites and could prove useful in the activation of their inactive proenzymes, although the activation conditions should be evaluated in detail to avoid undesirable digestions.

Whereas $1 \mu \mathrm{M}$ TLCK inhibited Lys-C activity in the supernatant, TLCK had no detectable inhibitory effect on hK8 up to $100 \mu \mathrm{M}$ (Figure 6). These data show that the enzyme activity detected upon incubation of pro-hK8 with Lys-C beads and treatment with TLCK originates from activated $\mathrm{hK} 8$ and not from contaminating Lys-C released from the beads.

hK8 cleaves synthetic substrates containing either Arg or Lys residues at their $\mathrm{P} 1$ position (Table 1). This activity corresponds to a trypsin-like specificity, but the specificity pattern is different compared to other trypsin-like proteases, including trypsin, thrombin, plasma kallikrein, urokinase and hK2 (Kishi et al., unpublished data). Recently, enzyme analysis of recombinant hK8 using synthetic substrates was reported (Rajapakse et al., 2005). The substrate specificities observed were very similar to those found in this study. Minor differences could be due to the different hK8 production protocol, since Rajapakse et al. expressed the protease in E. coli and used a subsequent refolding protocol to obtain active hK8. mK8 was reported to show an up to five-fold preference for P1 Arg over Lys (Shimizu et al., 1998). 
Boc-Val-Pro-Arg-AMC and Tos-Gly-Pro-Lys-AMC share Pro at P2. Although the main difference between these substrates is the P1 amino acid, there is a more than $30-$ fold difference between their $k_{\text {cat }} / K_{m}$ ratios for $\mathrm{hK} 8$. This difference is in agreement with the notion that hK8 prefers Arg at P1 position over Lys, and this preference might be stronger than that of $\mathrm{mK} 8$. Whereas the expression of $\mathrm{mK} 8$ in mouse brain was detected at the protein level (Shimizu et al., 1998), hK8 was not found to be expressed in appreciable amounts in brain tissue (Kishi et al., 2003b). These characteristic differences between hK8 and mK8 may indicate a difference in their physiological functions.

Primary substrate specificity analysis has been reported for the new members of the human tissue kallikrein family, hK4, 5, 6, 7, 11, 13, and 14 (Egelrud, 1993; Takayama et al., 2001; Magklara et al., 2003; Kapadia et al., 2004; Felber et al., 2005; Michael et al., 2005; Luo et al., 2006). All of them demonstrated trypsin-like activity, with the exception of the chymotrypsin-like protease hK7. A comparison of their substrate specificities is complicated by the use of very diverse buffer and substrate conditions. Nevertheless, Boc-Val-Pro-Arg-AMC was a favored substrate for these kallikreins. This substrate might therefore be a promising candidate to test the enzyme activity of uncharacterized trypsin-like kallikreins, such as hK10, 12 and 15. hK4, 5, 6, 7, 11, 13, and 14 all clearly favored a P1 Arg over a P1 Lys residue, and weak selectivity for Lys was only reported for hK4, 8, 13 and 14. Nevertheless, these weak P1 Lys specificities could be physiologically important, since these proteases are suggested to be part of an activation cascade involving various kallikreins (Yousef and Diamandis, 2002) and 7 out of 12 new human kallikreins have P1 Lys at the predicted activation site.

The influence of metal ions on hK8 activity was tested using six metal salts. $\mathrm{Na}^{+}$had no detectable effect on hK8 activity at up to $1 \mathrm{M}$. The $\mathrm{K}^{+}$concentration in serum (3.4-5.0 mm; Basu et al., 2004) is much lower than the concentration required for hK8 activation (Figure 5A). Therefore, these metal ions are not expected to influence hK8 activity under physiological conditions. Serum concentrations of $\mathrm{Ca}^{2+}(2.1-2.5 \mathrm{mM})$ and $\mathrm{Mg}^{2+}(0.7-1.0 \mathrm{mM})$, on the other hand, are higher than the concentrations required for increased hK8 activity and might be important in regulating hK8 activity under physiological conditions.

Trypsin is known to have a $\mathrm{Ca}^{2+}$-binding site (Bode and Schwager, 1975). $\mathrm{Ca}^{2+}$ binding stabilizes the trypsin structure and enhances its enzyme activity (Russin et al., 1974). $\mathrm{Ca}^{2+}$ binding also stimulates the activities of chymotrypsin and subtilisin. As described for these proteases, increased hK8 activity may be caused by stabilization of the enzyme structure induced by $\mathrm{Ca}^{2+}$ binding. Amino-acid sequence alignment of trypsin, mK8 and hK8, and structural comparison of trypsin and mK8 (Yoshida et al., 1998; Kishi et al., 1999) showed no insertions or deletions within the $\mathrm{Ca}^{2+}$-binding loop region among these enzymes. Using structural analysis of trypsin complexed with $\mathrm{Ca}^{2+}$ (Bode and Schwager, 1975), it was shown that this ion associates with five amino acids on a loop of trypsin with five coordinate bonds. Two out of these five amino acids, Asn72 and Val75 of trypsin, associate with $\mathrm{Ca}^{2+}$ via their carbonyl oxygens. These residues are replaced by Ser72 and Asn75 in hK8, which would not present any particular obstacle for $\mathrm{Ca}^{2+}$ binding. The third amino acid involved in binding, GIn80 of trypsin, is replaced by Glu80 in hK8; these residues share the same carbonyl and could form the same coordinate bond. For the replacement of Gln70 and Glu77 in trypsin by Asp70 and Asp77 in hK8, both of the distances between these residues and $\mathrm{Ca}^{2+}$ would be 1-1.5 $\AA$ shorter than the original distances to $\mathrm{Ca}^{2+}$ for trypsin. However, these distance differences might be made up by the interaction between Asp and internal water molecules (Bode and Schwager, 1975). Therefore, hK8 may possess a similar $\mathrm{Ca}^{2+}$-binding mechanism as described for trypsin.

Increased hK8 concentrations were found in serum from $60 \%$ of ovarian cancer patients compared to controls, which indicates that hK8 may be a candidate serum biomarker for this cancer (Kishi et al., 2003a). One type of ovarian cancer, hypercalcemic-type small cell carcinoma of the ovary, shows higher $\mathrm{Ca}^{2+}$ serum concentrations (Walt et al., 2001). In these ovarian cancer patients, hK8 activity could be increased and might be associated with carcinoma development and metastasis, as reported for other proteases.

It has been reported that $\mathrm{Zn}^{2+}$ inhibits hK2 (Lovgren et al., 1999), hK3 (Watt et al., 1986), hK5 (Brattsand et al., 2005), hK7 (Franzke et al., 1996), and hK14 (Brattsand et al., 2005). The predicted $\mathrm{Zn}^{2+}$-binding sites of hK2 and hK3 are composed of three His residues (Villoutreix et al., 1994; Lovgren et al., 1999), but sequence analysis shows that hK8 has only one His residue close to these corresponding positions (Yousef and Diamandis, 2001). hK5, 7 and 14 also possess only one His residue. The mechanism by which $\mathrm{Zn}^{2+}$ inhibits hK5, 7, 8, and 14 would therefore be expected to be different from that proposed for hK2 and 3.

A similar inhibitor profile for hK8 was found by Rajapakse et al. (2005). Among the protease inhibitors tested in the current study, antipain, leupeptin and TLCK are known as trypsin-like protease inhibitors containing Arg or Lys in the P1 position. The order of these inhibitors for activity against trypsin has generally been reported as leupeptin>antipain>TLCK (Jeohn et al., 1995; Valaitis, 1995; Ahsan and Watabe, 2001; Yousef and Diamandis, 2001). Although hK8 has trypsin-like specificity, TLCK does not inhibit this enzyme up to a concentration of $100 \mu \mathrm{M}$ and antipain was a better inhibitor of hK8 than leupeptin (Figure 6). The inhibition profile is therefore quite different from that observed for trypsin. An unexpected result for these inhibitor assays is that chymostatin inhibition of hK8 activity is eight-fold greater than for leupeptin (Figure 6). Chymostatin is an inhibitor of chymotrypsin-like proteases (Umezawa, 1976). Weak effects against trypsin-like activity have been reported for chymostatin, but these effects were always weaker than those observed for trypsin-like inhibitors (Jeohn et al., 1995; Valaitis, 1995). Chymostatin was also reported to have inhibitory activity against $\mathrm{mK} 8$, but the inhibitory activity was lower than for leupeptin (Shimizu et al., 1998). These data show hK8 inhibitor profile differences 
not only from trypsin, but also from mK8. These differences in enzyme profiles would support the hypothesis that hK8 might have different physiological functions than mK8. Moreover, it cannot be ruled out that hK8 has dual substrate specificity, as described for hK1 (Fiedler and Leysath, 1979) and hK14 (Brattsand et al., 2005; Felber et al., 2005), even if no activity was detectable for hK8 using the chymotrypsin substrate Suc-Ala-Ala-Pro-PheAMC. To answer this question, more detailed specificity analysis (Cloutier et al., 2002; Felber et al., 2005) or structural analysis (Laxmikanthan et al., 2005) is necessary.

In summary, pro-hK8 was activated using Lys-C and the specificity was found to be trypsin-like. These data are useful in our efforts to identify natural substrates and physiological functions for this newly described enzyme.

\section{Materials and methods}

\section{Materials}

Boc-Val-Pro-Arg-7-amido-4-methylcoumarin (AMC; thrombin substrate), Tos-Gly-Pro-Lys-AMC (plasmin substrate) and ZPhe-Arg-AMC (plasma kallikrein substrate) were from Bachem (Bubendorf, Switzerland). MeSuc-Ala-Ala-Pro-Val-AMC (elastase substrate), Suc-Ala-Ala-Pro-Phe-AMC (chymotrypsin substrate), Z-Gly-Gly-Arg-AMC (urokinase substrate) and tosyl lysyl chloromethyl ketone (TLCK) were from Calbiochem (VWR International AG, Luzern, Switzerland). Lysyl endopeptidase (Lys-C) was purchased from Wako Pure Chemical Industries, Ltd. (Osaka, Japan). Cyanogen bromide (CNBr)-activated Sepharose 4B was from Amersham Biosciences (Dubendorf, Germany). Antipain-dihydrochloride, bestatin, chymostatin, L-trans-epoxysuccinyl-leucylamide-(4-guanidino)-butane (E-64) and phosphoramidon were from Roche Diagnostics ( $F$. Hoffmann-La Roche Ltd., Basel, Switzerland). Ethylenediaminetetraacetic acid disodium salt $\left(E D T A-\mathrm{Na}_{2}\right)$ and leupeptin were purchased from Fluka (Buchs, Switzerland). Horseradish peroxidase (HRP)-conjugated goat anti-rabbit IgG was purchased from Jackson ImmunoResearch Inc. (West Grove, PA, USA). Recombinant pro-hK8 (Kishi et al., 2003b) and the $\alpha 1$-antichymotrypsin variant ACT(PCI) (Cloutier et al., 2004) were prepared as described elsewhere. All other reagents used were of analytical grade.

\section{Preparation of Lys-C conjugated beads}

Lys-C conjugated beads were prepared according to the supplier's instructions. Briefly, one vial of Lys-C $(3 \mathrm{U})$ was conjugated to $1 \mathrm{ml}$ of swollen $\mathrm{CNBr}$ beads at $4^{\circ} \mathrm{C}$ overnight. The efficiency of the coupling reaction was monitored by measuring total protein concentration in the supernatant before and after the reaction, using absorbance at $280 \mathrm{~nm}$. By measuring the decrease in protein concentration in the supernatant of the coupling reaction, the binding efficiency was estimated as approximately $45 \%$. Therefore, the quantity of Lys-C on the beads was estimated to $1.35 \mathrm{U} / \mathrm{ml}$. The activity of Lys-C conjugated on the beads was confirmed using the Lys-C specific synthetic substrate Tos-Gly-Pro-Lys-AMC (data not shown).

\section{Conditioning of hK8 activation with Lys-C conjugated beads}

A 200- $\mu$ l aliquot of the purified pro-hK8 (1 $\mu \mathrm{M}$ in $10 \mathrm{~mm}$ HEPES buffer, $\mathrm{pH} 7.4$ containing $500 \mathrm{~mm} \mathrm{NaCl}$ ) was mixed with $2.5 \mu \mathrm{l}$ of Lys-C conjugated beads. The mixture was incubated at $37^{\circ} \mathrm{C}$ on a rotating wheel to activate hK8. Then $30 \mu \mathrm{l}$ of the incubated mixture was sampled at $15,30,60$, and $120 \mathrm{~min}$ and centrifuged at $12000 \mathrm{~g}$ for $1 \mathrm{~min}$. Each supernatant was recovered, snapfrozen in liquid nitrogen and stored at $-80^{\circ} \mathrm{C}$ until enzyme and titration analysis. After thawing, $2.5 \mu \mathrm{l}$ of the supernatant samples was added to $47.5 \mu \mathrm{l}$ of $200 \mu \mathrm{M}$ Boc-Val-Pro-Arg-AMC prewarmed substrate solution (10 mM HEPES, pH 7.4 and $500 \mathrm{~mm}$ $\mathrm{NaCl}$ ) on a black 96-well microtiter plate. The fluorescence of released AMC was monitored (excitation at $340 \pm 15 \mathrm{~nm}$, emission at $485 \pm 10 \mathrm{~nm}$ ) using an FLx800 fluorometric plate reader (Bio-Tek Instruments, Inc., Winooski, VT, USA). A 10- $\mu$ l aliquot of each thawed sample was also mixed with $5 \mu \mathrm{l}$ of $4 \mu \mathrm{M}$ ACT(PCl) solution containing $50 \mathrm{~mm}$ Tris- $\mathrm{HCl}, \mathrm{pH} 8.0$ (at $37^{\circ} \mathrm{C}$ ) containing $500 \mathrm{~mm} \mathrm{NaCl}$ and $0.05 \%$ Triton X-100 [hK8/ACT(PCl) molar ratio of 1:2] or $5 \mu \mathrm{l}$ of the same buffer solution lacking $\mathrm{ACT}(\mathrm{PCl})$. The samples were incubated at $37^{\circ} \mathrm{C}$ for $5 \mathrm{~h}$ and then mixed with $5 \mu$ l of $4 \times$ sodium dodecyl sulfate (SDS) sample buffer without reducing reagent and incubated at $95^{\circ} \mathrm{C}$ for $10 \mathrm{~min}$. The samples were resolved by $10 \%$ SDS-PAGE followed by Western blot analysis with rabbit anti-hK8 antibody (1/5000 dilution; Kishi et al., 2003b) and HRP-conjugated goat anti-rabbit IgG (1/10 000 dilution) as the primary and secondary antibodies, respectively. The HRP activity was detected on X-ray films using $\mathrm{ECL}^{\mathrm{Tm}}$ Western blotting detection reagents (Amersham Bioscience).

\section{Inhibition of Lys-C activity in supernatant by TLCK}

The conditions for inhibition of Lys-C activity in supernatants were evaluated using TLCK, an inhibitor specific for Lys-C. Aliquots of $12.5 \mu \mathrm{l}$ of Lys-C beads were mixed with $1 \mathrm{ml}$ of $10 \mathrm{~mm}$ HEPES buffer, $\mathrm{pH} 7.4$ containing $500 \mathrm{~mm} \mathrm{NaCl}$ and incubated at $37^{\circ} \mathrm{C}$ for $45 \mathrm{~min}$. The mixture was centrifuged at $12000 \mathrm{~g}$ for $1 \mathrm{~min}$. Then $90 \mu \mathrm{l}$ of the supernatant was mixed with $10 \mu \mathrm{l}$ of a series of TLCK solutions (final concentration $10^{-9}-10^{-5} \mathrm{M}$ ) and incubated at room temperature for $40 \mathrm{~min}$. A $90-\mu \mathrm{l}$ aliquot of each sample was applied to a 96-well black plate and mixed with $10 \mu \mathrm{l}$ of $1 \mathrm{~mm}$ Tos-Gly-Pro-Lys-AMC solution. The fluorescence signal was monitored as described above.

\section{Activation of recombinant hK8}

A $20-\mathrm{ml}$ aliquot of $1 \mu \mathrm{M}$ pro-hK8 was activated using $250 \mu \mathrm{l}$ of Lys-C conjugated beads for $45 \mathrm{~min}$ at $37^{\circ} \mathrm{C}$ with rotation. The supernatant was recovered as previously described. The recovered sample was mixed with TLCK solution (final concentration $1 \mu \mathrm{M}$ ) and incubated at room temperature for $40 \mathrm{~min}$. The mixture was concentrated to $50 \mu \mathrm{M}$ using Centricon ${ }^{\mathrm{TM}}$ YM-10 (Millipore, Billerica, CA, USA), frozen in liquid nitrogen and stored at $-80^{\circ} \mathrm{C}$. The percentage of active hK8 in the sample was evaluated by Western blotting analysis with $\mathrm{ACT}(\mathrm{PCl})$ titration [hK8/ $\mathrm{ACT}(\mathrm{PCl})$ molar ratio of 1:10]. The activities of activated hK8 (act-hK8) samples treated with and without TLCK were also compared using Boc-Val-Pro-Arg-AMC as substrate.

\section{Amino-terminal sequencing of pro- and active hK8}

Samples of 100 pmol of pro- and active hK8 were blotted onto polyvinylidene fluoride (PVDF) membrane using Prosorb ${ }^{T M}$ cartridges (Perkin Elmer Life and Analytical Sciences, Inc., Boston, MA, USA). The blotted samples were sequenced by standard Edman digestion to identify the $\mathrm{N}$-terminal sequences.

\section{Determination of pH optimum for active hK8}

The $\mathrm{pH}$ optimum for active hK8 was determined using a series of buffers ( $\mathrm{pH}$ 5.0-10.0). A four-buffer salt mixture, $\mathrm{CH}_{3} \mathrm{COOH}$ (25 mM), 2-(N-morpholino)ethanesulfonic acid (MES; $25 \mathrm{~mm}$ ), Tris (75 mM), and glycine (25 mM) were prepared and added to $\mathrm{NaCl}$ 
(150 mm) and Triton X-100 (0.05\%). The $\mathrm{pH}$ was adjusted by addition of $\mathrm{HCl}$ or $\mathrm{NaOH}$. A solution of $10 \mu \mathrm{M}$ Boc-Val-Pro-ArgAMC in each pH buffer $(48 \mu l)$ was applied to a 96-well black microtiter plate. The plate was covered to prevent sample evaporation and was incubated at $37^{\circ} \mathrm{C}$ for $20 \mathrm{~min}$. Then $2 \mu \mathrm{l}$ of $2.5 \mu \mathrm{M}$ hK8 solution was added to each well and the fluorescence signal was monitored as described above. $k_{\text {cat }} / K_{\mathrm{m}}$ values were calculated as previously described (Elmoujahed et al., 1990) and plotted against each $\mathrm{pH}$ value.

\section{Enzyme analysis of substrate specificity}

hK8 activity was tested with six commercial synthetic AMC-containing substrates and their $k_{\text {cat }} / K_{\mathrm{m}}$ values were calculated as previously described (Elmoujahed et al., 1990). Each substrate solution was prepared with $50 \mathrm{~mm}$ Tris- $\mathrm{HCl}, \mathrm{pH} 8.5$ at $37^{\circ} \mathrm{C}$ containing $150 \mathrm{mM} \mathrm{NaCl}$ and $0.1 \%$ bovine serum albumin (BSA) (final substrate concentration $10 \mu \mathrm{M}$ ) and applied to black 96well microtiter plates in a total volume of $48 \mu \mathrm{l}$. The plates were covered and incubated at $37^{\circ} \mathrm{C}$ for $20 \mathrm{~min}$. Then $2 \mu \mathrm{l}$ of $2.5 \mu \mathrm{M}$ hK8 solution was added to each well and the fluorescence was monitored as previously described. These analyses were performed three times for each substrate-hK8 combination. Substrate specificities were calculated by direct $k_{\text {cat }} / K_{\mathrm{m}}$ determination as previously described (Elmoujahed et al., 1990). All data were analyzed using Microsoft Excel 2000 (Redmond, WA, USA). The standard error of the mean for each $k_{\mathrm{cat}} / K_{\mathrm{m}}$ was normalized by $t$-distribution with $t_{3-1}(0.1)$ (Campbell, 1989).

\section{Effect of metal ions}

The effect of metal ions as inhibitors for hK8 was evaluated using $10 \mu \mathrm{M}$ Boc-Val-Pro-Arg-AMC substrate solution in $50 \mathrm{~mm}$ Tris- $\mathrm{HCl}$ buffer, $\mathrm{pH} 8.5$ at $37^{\circ} \mathrm{C}$ containing $0.05 \%$ Triton X-100. The concentrations of metal salts tested were: $\mathrm{CaCl}_{2}, 10^{-8}-1 \mathrm{M}$; $\mathrm{MgCl}_{2}, 10^{-8}-1 \mathrm{M} ; \mathrm{MgSO}_{4}, 10^{-8}-10^{-2} \mathrm{M} ; \mathrm{KCl}, 10^{-5}-1 \mathrm{M} ; \mathrm{NaCl}, 10^{-2}$ $-1 \mathrm{M}$; $\mathrm{NiSO}_{4}, 10^{-8}-10^{-4} \mathrm{M}$; and $\mathrm{ZnSO}_{4}, 10^{-9}-10^{-4} \mathrm{M}$. Solutions of each metal concentration was applied onto black 96-well microtiter plates (volume $48 \mu \mathrm{l}$ ). The plates were covered and incubated at $37^{\circ} \mathrm{C}$ for $20 \mathrm{~min}$. Then $2 \mu \mathrm{l}$ of $2.5 \mu \mathrm{M}$ hK 8 solution was added to each well and the fluorescence signal was monitored as described above. Each condition was tested twice and each $\mathrm{IC}_{50}$ was evaluated using Microsoft Excel 2000.

\section{Effect of inhibitors}

The activities of inhibitors for hK8 were evaluated using $10 \mu \mathrm{M}$ Boc-Val-Pro-Arg-AMC substrate solution in $50 \mathrm{~mm}$ Tris- $\mathrm{HCl}$ buffer, $\mathrm{pH} 8.5$ at $37^{\circ} \mathrm{C}$ containing $0.05 \%$ Triton $\mathrm{X}-100$. The concentrations of the inhibitors antipain, bestatin, chymostatin, E-64, leupeptin, phosphoramidon and TLCK tested were $10^{-9}-10^{-4} \mathrm{M}$. Enzyme and statistical analyses were carried out using the same procedure as described for metal-ion experiments.

\section{Acknowledgments}

We thank Professor Takeharu Masaki (Ibaraki University, Japan) for technical advice on Lys-C specificity.

\section{References}

Ahsan, M.N. and Watabe, S. (2001). Kinetic and structural properties of two isoforms of trypsin isolated from the viscera of Japanese anchovy, Engraulis japonicus. J. Protein Chem. $20,49-58$.
Akita, H., Matsuyama, T., Iso, H., Sugita, M., and Yoshida, S. (1997). Effects of oxidative stress on the expression of limbic-specific protease neuropsin and avoidance learning in mice. Brain Res. 769, 86-96.

Basu, A., Dillon, R.D., Taylor, R., Davison, J.M., and Marshall, S.M. (2004). Is normalisation of serum potassium and magnesium always necessary in Gitelman syndrome for a successful obstetric outcome? BJOG 111, 630-634.

Bernett, M.J., Blaber, S.I., Scarisbrick, I.A., Dhanarajan, P., Thompson, S.M., and Blaber, M. (2002). Crystal structure and biochemical characterization of human kallikrein 6 reveals that a trypsin-like kallikrein is expressed in the central nervous system. J. Biol. Chem. 277, 24562-24570.

Bode, W. and Schwager, P. (1975). The single calcium-binding site of crystalline bovine $\beta$-trypsin. FEBS Lett. $56,139-143$.

Borgono, C.A. and Diamandis, E.P. (2004). The emerging roles of human tissue kallikreins in cancer. Nat. Rev. Cancer 4 , 876-890.

Borgono, C.A., Grass, L., Soosaipillai, A., Yousef, G.M., Petraki, C.D., Howarth, D.H., Fracchioli, S., Katsaros, D., and Diamandis, E.P. (2003). Human kallikrein 14: a new potential biomarker for ovarian and breast cancer. Cancer Res. 63, 9032-9041.

Brattsand, M., Stefansson, K., Lundh, C., Haasum, Y., and Egelrud, T. (2005). A proteolytic cascade of kallikreins in the stratum corneum. J. Invest. Dermatol. 124, 198-203.

Campbell, R.C. (1989). Statistics for Biologists, 3rd ed. (Cambridge, UK: Cambridge University Press).

Cane, S., Bignotti, E., Bellone, S., Palmieri, M., De las Casas, L., Roman, J.J., Pecorelli, S., Cannon, M.J., O'Brien, T., and Santin, A.D. (2004). The novel serine protease tumor-associated differentially expressed gene-14 (KLK8/Neuropsin/ Ovasin) is highly overexpressed in cervical cancer. Am. J. Obstet. Gynecol. 190, 60-66.

Chen, Z.L., Yoshida, S., Kato, K., Momota, Y., Suzuki, J., Tanaka, T., Ito, J., Nishino, H., Aimoto, S., Kiyama, H., et al. (1995). Expression and activity-dependent changes of a novel limbic-serine protease gene in the hippocampus. J. Neurosci. 15, 5088-5097.

Cloutier, S.M., Chagas, J.R., Mach, J.P., Gygi, C.M., Leisinger, H.J., and Deperthes, D. (2002). Substrate specificity of human kallikrein 2 (hK2) as determined by phage display technology. Eur. J. Biochem. 269, 2747-2754.

Cloutier, S.M., Kundig, C., Felber, L.M., Fattah, O.M., Chagas, J.R., Gygi, C.M., Jichlinski, P., Leisinger, H.J., and Deperthes, D. (2004). Development of recombinant inhibitors specific to human kallikrein 2 using phage-display selected substrates. Eur. J. Biochem. 271, 607-613.

Davies, B.J., Pickard, B.S., Steel, M., Morris, R.G., and Lathe, R. (1998). Serine proteases in rodent hippocampus. J. Biol. Chem. 273, 23004-23011.

Deperthes, D., Chapdelaine, P., Tremblay, R.R., Brunet, C., Berton, J., Hebert, J., Lazure, C., and Dube, J.Y. (1995). Isolation of prostatic kallikrein hK2, also known as hGK-1, in human seminal plasma. Biochim. Biophys. Acta 1245, 311-316.

Diamandis, E.P., Yousef, G.M., Clements, J., Ashworth, L.K., Yoshida, S., Egelrud, T., Nelson, P.S., Shiosaka, S., Little, S., Lilja, H., et al. (2000a). New nomenclature for the human tissue kallikrein gene family. Clin. Chem. 46, 1855-1858.

Diamandis, E.P., Yousef, G.M., Soosaipillai, A.R., Grass, L., Porter, A., Little, S., and Sotiropoulou, G. (2000b). Immunofluorometric assay of human kallikrein 6 (zyme/protease M/ neurosin) and preliminary clinical applications. Clin. Biochem. 33, 369-375.

Diamandis, E.P., Okui, A., Mitsui, S., Luo, L.Y., Soosaipillai, A., Grass, L., Nakamura, T., Howarth, D.J., and Yamaguchi, N. (2002). Human kallikrein 11: a new biomarker of prostate and ovarian carcinoma. Cancer Res. 62, 295-300.

Egelrud, T. (1993). Purification and preliminary characterization of stratum corneum chymotryptic enzyme: a proteinase that may be involved in desquamation. J. Invest. Dermatol. 101, 200-204. 
Elmoujahed, A., Gutman, N., Brillard, M., and Gauthier, F. (1990). Substrate specificity of two kallikrein family gene products isolated from the rat submaxillary gland. FEBS Lett. 265, 137-140.

Felber, L.M., Borgono, C.A., Cloutier, S.M., Kundig, C., Kishi, T., Ribeiro Chagas, J., Jichlinski, P., Gygi, C.M., Leisinger, H.J., Diamandis, E.P., and Deperthes, D. (2005). Enzymatic profiling of human kallikrein 14 using phage-display substrate technology. Biol. Chem. 386, 291-298.

Fiedler, F. and Leysath, G. (1979). Substrate specificity of porcine pancreatic kallikrein. Adv. Exp. Med. Biol. 120A, 261-271.

Franzke, C.W., Baici, A., Bartels, J., Christophers, E., and Wiedow, O. (1996). Antileukoprotease inhibits stratum corneum chymotryptic enzyme. Evidence for a regulative function in desquamation. J. Biol. Chem. 271, 21886-21890.

Gomis-Ruth, F.X., Bayes, A., Sotiropoulou, G., Pampalakis, G., Tsetsenis, T., Villegas, V., Aviles, F.X., and Coll, M. (2002). The structure of human prokallikrein 6 reveals a novel activation mechanism for the kallikrein family. J. Biol. Chem. 277, 27273-27281.

Hansson, L., Stromqvist, M., Backman, A., Wallbrandt, P., Carlstein, A., and Egelrud, T. (1994). Cloning, expression, and characterization of stratum corneum chymotryptic enzyme. A skin-specific human serine proteinase. J. Biol. Chem. 269, 19420-19426.

Huntington, J.A., Read, R.J., and Carrell, R.W. (2000). Structure of a serpin-protease complex shows inhibition by deformation. Nature 407, 923-926.

Jeohn, G.H., Serizawa, S., Iwamatsu, A., and Takahashi, K. (1995). Isolation and characterization of gastric trypsin from the microsomal fraction of porcine gastric antral mucosa. J. Biol. Chem. 270, 14748-14755.

Kapadia, C., Chang, A., Sotiropoulou, G., Yousef, G.M., Grass, L., Soosaipillai, A., Xing, X., Howarth, D.H., and Diamandis, E.P. (2003). Human kallikrein 13: production and purification of recombinant protein and monoclonal and polyclonal antibodies, and development of a sensitive and specific immunofluorometric assay. Clin. Chem. 49, 77-86.

Kapadia, C., Yousef, G.M., Mellati, A.A., Magklara, A., Wasney, G.A., and Diamandis, E.P. (2004). Complex formation between human kallikrein 13 and serum protease inhibitors. Clin. Chim. Acta 339, 157-167.

Kishi, T., Kato, M., Shimizu, T., Kato, K., Matsumoto, K., Yoshida, S., Shiosaka, S., and Hakoshima, T. (1999). Crystal structure of neuropsin, a hippocampal protease involved in kindling epileptogenesis. J. Biol. Chem. 274, 4220-4224.

Kishi, T., Grass, L., Soosaipillai, A., Scorilas, A., Harbeck, N., Schmalfeldt, B., Dorn, J., Mysliwiec, M., Schmitt, M., and Diamandis, E.P. (2003a). Human kallikrein 8, a novel biomarker for ovarian carcinoma. Cancer Res. 63, 2771-2774.

Kishi, T., Grass, L., Soosaipillai, A., Shimizu-Okabe, C., and Diamandis, E.P. (2003b). Human kallikrein 8: immunoassay development and identification in tissue extracts and biological fluids. Clin. Chem. 49, 87-96.

Kishi, T., Soosaipillai, A., Grass, L., Little, S.P., Johnstone, E.M., and Diamandis, E.P. (2004). Development of an immunofluorometric assay and quantification of human kallikrein 7 in tissue extracts and biological fluids. Clin. Chem. 50, 709-716.

Laxmikanthan, G., Blaber, S.I., Bernett, M.J., Scarisbrick, I.A., Juliano, M.A., and Blaber, M. (2005). $1.70 \AA$ X-ray structure of human apo kallikrein 1: structural changes upon peptide inhibitor/substrate binding. Proteins 58, 802-814.

Lovgren, J., Airas, K., and Lilja, H. (1999). Enzymatic action of human glandular kallikrein 2 (hK2). Substrate specificity and regulation by $\mathrm{Zn}^{2+}$ and extracellular protease inhibitors. Eur. J. Biochem. 262, 781-789.

Luo, L.Y., Grass, L., Howarth, D.J., Thibault, P., Ong, H., and Diamandis, E.P. (2001). Immunofluorometric assay of human kallikrein 10 and its identification in biological fluids and tissues. Clin. Chem. 47, 237-246.
Luo, L.Y., Shan, S.J., Elliott, M.B., Soosaipillai, A., and Diamandis, E.P. (2006). Purification and characterization of human kallikrein 11 , a candidate prostate and ovarian cancer biomarker, from seminal plasma. Clin. Cancer Res. 12, 742-750.

Maeda, S. (1989). Expression of foreign genes in insects using baculovirus vectors. Annu. Rev. Entomol. 34, 351-372.

Magklara, A., Mellati, A.A., Wasney, G.A., Little, S.P., Sotiropoulou, G., Becker, G.W., and Diamandis, E.P. (2003). Characterization of the enzymatic activity of human kallikrein 6: autoactivation, substrate specificity, and regulation by inhibitors. Biochem. Biophys. Res. Commun. 307, 948-955.

Michael, I.P., Sotiropoulou, G., Pampalakis, G., Magklara, A., Ghosh, M., Wasney, G., and Diamandis, E.P. (2005). Biochemical and enzymatic characterization of human kallikrein 5 (hK5), a novel serine protease potentially involved in cancer progression. J. Biol. Chem. 280, 14628-14635.

Momota, Y., Yoshida, S., Ito, J., Shibata, M., Kato, K., Sakurai, K., Matsumoto, K., and Shiosaka, S. (1998). Blockade of neuropsin, a serine protease, ameliorates kindling epilepsy. Eur. J. Neurosci. 10, 760-764.

Obiezu, C.V., Shan, S.J., Soosaipillai, A., Luo, L.Y., Grass, L., Sotiropoulou, G., Petraki, C.D., Papanastasiou, P.A., Levesque, M.A., and Diamandis, E.P. (2005). Human kallikrein 4: quantitative study in tissues and evidence for its secretion into biological fluids. Clin. Chem. 51, 1432-1442.

Okabe, A., Momota, Y., Yoshida, S., Hirata, A., Ito, J., Nishino, H., and Shiosaka, S. (1996). Kindling induces neuropsin mRNA in the mouse brain. Brain Res. 728, 116-120.

Rajapakse, S., Ogiwara, K., Takano, N., Moriyama, A., and Takahashi, T. (2005). Biochemical characterization of human kallikrein 8 and its possible involvement in the degradation of extracellular matrix proteins. FEBS Lett. 579, 6879-6884.

Russin, D.J., Floyd, B.F., Toomey, T.P., Brady, A.H., and Awad, W.M. Jr. (1974). The proteolytic enzymes of the K-1 strain of Streptomyces griseus obtained from a commercial preparation (pronase). Stabilization of the trypsin component by calcium and guanidine. J. Biol. Chem. 249, 6144-6148.

Shimizu, C., Yoshida, S., Shibata, M., Kato, K., Momota, Y., Matsumoto, K., Shiosaka, T., Midorikawa, R., Kamachi, T., Kawabe, A., and Shiosaka, S. (1998). Characterization of recombinant and brain neuropsin, a plasticity-related serine protease. J. Biol. Chem. 273, 11189-11196.

Shimizu-Okabe, C., Yousef, G.M., Diamandis, E.P., Yoshida, S., Shiosaka, S., and Fahnestock, M. (2001). Expression of the kallikrein gene family in normal and Alzheimer's disease brain. Neuroreport 12, 2747-2751.

Stamey, T.A., Yang, N., Hay, A.R., McNeal, J.E., Freiha, F.S., and Redwine, E. (1987). Prostate-specific antigen as a serum marker for adenocarcinoma of the prostate. N. Engl. J. Med. 317, 909-916.

Takayama, T.K., McMullen, B.A., Nelson, P.S., Matsumura, M., and Fujikawa, K. (2001). Characterization of hK4 (prostase), a prostate-specific serine protease: activation of the precursor of prostate specific antigen (pro-PSA) and single-chain urokinase-type plasminogen activator and degradation of prostatic acid phosphatase. Biochemistry 40, 15341-15348.

Umezawa, H. (1976). Structures and activities of protease inhibitors of microbial origin. Methods Enzymol. 45, 678-695.

Underwood, L.J., Tanimoto, H., Wang, Y., Shigemasa, K., Parmley, T.H., and O'Brien, T.J. (1999). Cloning of tumor-associated differentially expressed gene-14, a novel serine protease overexpressed by ovarian carcinoma. Cancer Res. 59, 4435-4439.

Valaitis, A.P. (1995). Gypsy moth midgut proteinases: purification and characterization of luminal trypsin, elastase and the brush border membrane leucine aminopeptidase. Insect Biochem. Mol. Biol. 25, 139-149.

Villoutreix, B.O., Getzoff, E.D., and Griffin, J.H. (1994). A structural model for the prostate disease marker, human prostatespecific antigen. Protein Sci. 3, 2033-2044. 
Walt, H., Hornung, R., Fink, D., Dobler-Girdziunaite, D., Stallmach, T., Spycher, M.A., Maly, F., Haller, U., and Burki, N. (2001). Hypercalcemic-type of small cell carcinoma of the ovary: characterization of a new tumor line. Anticancer Res. 21, 3253-3259.

Watt, K.W., Lee, P.J., M'Timkulu, T., Chan, W.P., and Loor, R. (1986). Human prostate-specific antigen: structural and functional similarity with serine proteases. Proc. Natl. Acad. Sci. USA 83, 3166-3170.

Yoshida, S., Taniguchi, M., Hirata, A., and Shiosaka, S. (1998). Sequence analysis and expression of human neuropsin cDNA and gene. Gene 213, 9-16.

Yousef, G.M. and Diamandis, E.P. (2001). The new human tissue kallikrein gene family: structure, function, and association to disease. Endocr. Rev. 22, 184-204.

Yousef, G.M. and Diamandis, E.P. (2002). Human tissue kallik- reins: a new enzymatic cascade pathway? Biol. Chem. 383, 1045-1057

Yousef, G.M., Polymeris, M.E., Grass, L., Soosaipillai, A., Chan, P.C., Scorilas, A., Borgono, C., Harbeck, N., Schmalfeldt, B., Dorn, J., et al. (2003). Human kallikrein 5: a potential novel serum biomarker for breast and ovarian cancer. Cancer Res. 63, 3958-3965.

Yousef, G.M., Borgono, C.A., Popalis, C., Yacoub, G.M., Polymeris, M.E., Soosaipillai, A., and Diamandis, E.P. (2004a). In silico analysis of kallikrein gene expression in pancreatic and colon cancers. Anticancer Res. 24, 43-51.

Yousef, G.M., Yacoub, G.M., Polymeris, M.E., Popalis, C., Soosaipillai, A., and Diamandis, E.P. (2004b). Kallikrein gene downregulation in breast cancer. Br. J. Cancer 90, 167-172.

Received November 30, 2005; accepted April 4, 2006 